\title{
Population structure in landrace barley (Hordeum vulgare L.) during the late 19th century crop failures in Fennoscandia
}

\author{
Nils E. G. Forsberg ${ }^{1,2} \cdot$ Matti W. Leino ${ }^{2,3,4} \cdot$ Jenny Hagenblad ${ }^{2}$
}

Received: 13 June 2019 / Revised: 24 September 2019 / Accepted: 25 September 2019 / Published online: 15 October 2019

(c) The Author(s), under exclusive licence to The Genetics Society 2019

\begin{abstract}
Agricultural disasters and the subsequent need for supply of relief seed can be expected to influence the genetic composition of crop plant populations. The consequences of disasters and seed relief have, however, rarely been studied since specimens sampled before the events are seldomly available. A series of crop failures struck northern Fennoscandia (Norway, Sweden and Finland) during the second half of the 19th century. In order to assess population genetic dynamics of landrace barley (Hordeum vulgare), and consequences of crop failure and possible seed relief during this time period, we genotyped seeds from 16 historical accessions originating from two time periods spanning the period of repeated crop failure. Reliable identification of genetic structuring is highly dependent on sampling regimes and detecting fine-scale geographic or temporal differentiation requires large sample sizes. The robustness of the results under different sampling regimes was evaluated by analyzing subsets of the data and an artificially pooled dataset. The results led to the conclusion that six individuals per accession were insufficient for reliable detection of the observed genetic structure. We found that population structure among the data was best explained by collection year of accessions, rather than geographic origin. The correlation with collection year indicated a change in genetic composition of landrace barley in the area after repeated crop failures, likely a consequence of introgression of relief seed in local populations. Identical genotypes were found to be shared among some accessions, suggesting founder effects and local seed exchange along known routes for trade and cultural exchange.
\end{abstract}

\section{Introduction}

Extreme climate events are a constant threat to low-yielding agricultural areas and understanding and predicting the long-term genetic effects on genetic composition after disasters and seed relief is important for food security

Supplementary information The online version of this article (https:// doi.org/10.1038/s41437-019-0277-0) contains supplementary material, which is available to authorized users.

Jenny Hagenblad

Jenny.Hagenblad@liu.se

1 Department of Biology, Norwegian University of Science and Technology, N-7491 Trondheim, Norway

2 IFM-Biology, Linköping University, SE-581 83 Linköping, Sweden

3 Nordiska museet, Swedish Museum of Cultural History, Box 27820, SE-115 93 Stockholm, Sweden

4 The Archaeological Research Laboratory, Stockholm University, SE-106 91 Stockholm, Sweden
(Ferguson et al. 2012). While the status and recovery of crops in the aftermath of recent disasters and conflicts have been studied (e.g., Sperling 2001; Jones et al. 2002; Ferguson et al. 2012; Fuentes et al. 2012) most studies have been from contemporary Africa.

In the northern parts of Fennoscandia (Norway, Sweden and Finland), above the 65th parallel, lies the northernmost limit of cereal cultivation (Bjørnstad and Abay 2010). Archaeobotanical studies have shown that cereal cultivation has a long history in the region (Bergman and Hörnberg 2015; Josefsson et al. 2017), with finds dating back to at least $500 \mathrm{BC}$ along the coast and $1400 \mathrm{AD}$ in the interior (Bergman and Hörnberg 2015). The region covers vast land areas but agricultural land is restricted to small and isolated locations. Due to the harsh climatic conditions in the region the only cereal species with sufficient hardiness for cultivation is barley (Hordeum vulgare) (Bjørnstad and Abay 2010).

Barley is a diploid species that is almost completely selffertilizing across a range of environments (Abdel-Ghani et al. 2004). The landraces grown in Northern Fennoscandia were well-known for their adaption to the short growing 
season through fast maturation but at the cost of smaller harvests. Agricultural literature from the late 19th and early 20th century tell of an original type of barley cultivated in this region known as "lappkorn" (Lapponian barley) or "finnkorn" (Finnish barley) (Grotenfelt 1896; Hellström 1917). Indeed, Forsberg et al. (2015) studying as few as six individuals from each of 31 historical accessions from all over Fennoscandia and Denmark, showed how six-row barley from northernmost Fennoscandia was, as a group, genetically differentiated from six-row barley elsewhere in the region. Similar results were obtained by LempiäinenAvci et al. (2018) focusing on Finnish barley.

In spite of the barley's well-known hardiness, Fennoscandia has historically repeatedly suffered from crop failures (Dribe et al. 2015). Extreme weather in the region during the years 1866-1869 resulted in several consecutive years of crop failure (Häger et al. 1978; Nelson 1988). In 1867 the spring was so cold that anomalies of such a magnitude are only expected to occur a few times in a millennium (Jantunen and Ruosteenoja 2000). In addition, autumn came early this year imposing harvest of yet unripe cereals. The following years were only marginally better (Nelson 1988). The poor harvests during this period contributed to a culmination in emigration from Sweden to America (Grym 1959; Nelson 1988) and in northern Finland the human population shrank by 5\% from 1865 to 1870 from the combined effects of emigration, starvation and starvation-related disease (Tilastokeskus 1875; Pitkänen 1992). Yield rates, expressed as the ratio of harvest volume compared with seed volume, from the Norrbotten region in northernmost Sweden for the years 1865-1900, reveal that crop failures also occurred in 1877, 1888 and 1892 (Statistiska centralbyrån 1856-1905). Yield rates from Finland and Norway show a similar general pattern, with consecutive years with low yield during the second half of the 1860s and additional sporadic years with poor yield during the period 1870-1900 (Tilastokeskus 1875; Nelson 1988). The drastic and frequent loss of seed from crop failure may have resulted in a loss of indigenous genetic barley diversity through population bottlenecks. During the crop failure in northern Sweden 1867-1869, both national and international efforts were made to alleviate famine (Häger et al. 1978; Nelson 1988). Emergency relief was mostly provided in the form of flour, not seed, and the seed import from outside the region was not particularly increased during the period (Nelson 1988). Whether farmers stayed true to their local landraces and saved what little harvest they had for seeding the next year's crop or whether what seed import there was led to the addition of novel genetic diversity to the local landraces is not known.

Few extant landraces are available from Northern Fennoscandia. In contrast, the area is unusually well endowed when it comes to accessions of historical seed samples (Leino et al. 2009; Leino 2010). During the late 19th century the northernmost Fennoscandia was the target of several seed collection missions with the purpose of obtaining material to display at fairs and exhibitions (Leino 2010). The specimens, mostly six-row barley, gathered during some of these missions remain at museums across Fennoscandia (Leino et al. 2009; Leino 2010). The age of the material ensures that it represents genuine landrace barley, as plant improvement for sixrow barley in Fennoscandia did not begin until the early 20th century (Osvald 1959). Although the seeds are no longer viable, genetic analysis of DNA is possible (e.g., Leino et al. 2009; Forsberg et al. 2015). Historical accessions collected from northernmost Fennoscandia generally fall into two distinct temporal classes, 1867-1870 and 1893-1896, thus spanning the years of crop failure. This provides an opportunity to study the famine years' effect on the crop's genetic composition. The Fennoscandian crop failures of the late 19th century can thus serve as an excellent case study of how the genetic composition of landrace crops changes after a period of continuous poor harvests.

Studies of genetic structure and spatial distribution of crops have received considerable attention in recent years (e.g., Olsen and Schaal 1999; Londo et al. 2006; Jones et al. 2011; Oliveira et al. 2012, Yelome et al. 2018). In most cases such studies have relied on genotyping single seeds or pooled DNA from multiple seeds thereby increasing the number of accessions or populations that can be screened. Other studies have prioritized genotyping of multiple individuals of each population (e.g. Papa et al. 1998; Demissie and Bjørnstad 1997; Leino and Hagenblad 2010; Forsberg et al. 2015, Hagenblad et al. 2017). Computer simulations and microsatellite data from Arabidopsis thaliana suggests that the number of sampled individuals per accession can affect the ability to detect genetic clusters (Fogelqvist et al. 2010). The power to detect genetic structuring over short periods of time or limited geographical ranges, where the genetic variation within populations is much greater than the diversity among populations, may thus be strongly affected by the sampling regime.

In this study we have investigated the temporal consequences of crop failure and subsequent relief on the genetic composition of 19th century landrace barley in Northern Fennoscandia. To facilitate detection of relatively small effects on a regional scale we sampled up to 20 individuals from each accession. By creating subsets and artificially mimicking the output from single seed sampling and pooling of DNA extracts we also assessed the effect of different sampling regimes on the ability to detect genetic clustering. 


\section{Materials and methods}

\section{Sample selection}

Twenty grains from each of 16 accessions of landrace six-row barley were chosen for the study (Table 1). Some of the specimens had previously been part of the Forsberg et al. (2015) study, but new accessions from northernmost Fennoscandia were added and the number of grains from each accession was more than tripled to increase the power to detect fine-scale genetic structure beyond that of Forsberg et al. (2015). The accessions were obtained from three different 19th century seed collections; Troms $\varnothing$ University Museum in Norway (TR, four accessions), Mustiala Agricultural College in Finland (MU, two accessions) and the Swedish Museum of Cultural History in Sweden (NM, ten accessions) (Leino 2010). Grain had been gathered from farmers during two distinct 3-year periods in the 19th century that were classified into an "Early" (1867-1870, seven accessions) and a "Late" (1893-1896, nine accessions) class (Table 1). Maps for geographic representation of accession origin and geographic genetic structure were generated using ArcGIS (ESRI, Redlands, CA, USA) with geographic base data from the "ESRI data and maps v. 9.3" database (2008).

\section{DNA-analysis}

DNA was extracted from individual seeds from each accession using FastDNA Spin Kits and the FastPrep Instrument (MP Biochemicals, Solon, OH, USA). Extractions were performed at a laboratory separate from that where SNP genotyping was carried out to reduce the risk of contamination. A negative control was included in each extraction series and a total of nine negative controls were included in the genotyping. Genotyping was performed using an Illumina Golden Gate assay (Illumina Inc., San Diego, CA, USA) for the C-384 barley SNP set detailed by Moragues et al. (2010). The robustness of the C-384 SNP set on historical barley landrace material was shown in Forsberg et al. (2015).

The resulting data were processed and studied with the BeadStudio 3.1.3.0 software package (Illumina Inc., San Diego, CA, USA). Quality control based on CG10 scores led to the exclusion of 26 low-performance samples, including all nine negative controls. Samples with more than $25 \%$ missing data (39 samples), markers with more than $20 \%$ missing data (92 SNPs) and monomorphic SNPs (140 SNPs) were also excluded, in that order. High-quality genotypes for 152 SNP variable markers were obtained from 275 individuals.

\section{Genetic diversity}

Within-accession genetic diversity was calculated as Nei's $\mathrm{h}$ (Nei 1973), using a purpose-written script in the statistical software R (R development core team 2013, version 3.0.2). The distribution of genetic diversity was further studied through AMOVA (Excoffier et al. 1992) and $F_{\mathrm{ST}}$ statistics (Weir and Cockerham 1984) between pairs of accessions. Pairwise $F_{\mathrm{ST}}$ was also calculated between the Early and Late classes of accessions and between groups defined by country of origin. $F_{\mathrm{ST}}$ significance was estimated using permutation tests with 1000 permutations. AMOVA was performed with country of origin and age class as discrete groups. The proportion of total genotype sharing, i.e., individuals that were scored as identical, within and between accessions was also calculated. AMOVA, pairwise $F_{\mathrm{ST}}$ and total genotype sharing were calculated using the Arlequin 3.5 software (Excoffier and Lischer 2010). Arlequin was set to infer haplotype definitions from the distance matrix and to allow for $25 \%$ missing data per loci.

\section{Population structure}

Population structure was assessed in $\mathrm{R}$ using principal component analysis (PCA) and the SNP data was analyzed both at an accession level and on an individual level. For the individual level, each homozygous SNP was treated as either 1 or 0 and missing data were replaced with the allele frequency in the full dataset of the allele designated as ' 1 '. For the accession-level PCA, allele frequencies of each accession for each of the SNPs were calculated and treated as independent variables. PCoA was included for comparison with PCA and was assessed using the ape R package (Popescu et al 2012). PC dispersion, the mean pairwise distance in PC-space between individuals within accessions, was calculated as the average distance between individuals belonging to the same accession in a multidimensional space calculated from all principal components according to Forsberg et al. (2015). Population clustering was explored using two different methods, structure (Pritchard et al. 2000; Falush et al. 2007, version 2.3.3) and Discriminant Analysis of Principal Components, DAPC (Jombart et al. 2010). Genotype data was analyzed as haploid, as suggested for structure clustering for predominantly self-fertilizing species by Nordborg et al. (2005), treating heterozygous loci as missing data. The admixture model was used and simulations were run with a burn-in period set to 25,000 iterations and estimates based on the following 50,000 iterations for one through ten clusters $(K=1$ to 10$)$. Potential multimodality of the clustering analyses was resolved by merging 20 runs for each value of $K$ using the CLUMPP software (Jakobsson and Rosenberg 2007). 
Table 1 Accession list with geographical information and genetic diversity for the accessions used in the study

\begin{tabular}{|c|c|c|c|c|c|c|c|c|c|c|c|}
\hline Accession & Origin & Country & Harvest year & Age class & Lat & Long & $\begin{array}{l}\text { Altitude } \\
\text { (m.a.s.) }\end{array}$ & $N^{\mathrm{a}}$ & $\begin{array}{l}\text { Nei's } \\
\text { h }\end{array}$ & $\begin{array}{l}\text { Mean PC- } \\
\text { dispersion }\end{array}$ & $\begin{array}{l}\text { Var PC- } \\
\text { dispersion }\end{array}$ \\
\hline TR1 & Storjord & Norway & 1869 & Early & 68.2 & 16.1 & 10 & 18 & 0.104 & 3.864 & 0.459 \\
\hline TR5 & Ibestad & Norway & 1869 & Early & 68.8 & 17.2 & 10 & 16 & 0.084 & 3.547 & 0.379 \\
\hline TR7 & Balsfjord & Norway & 1869 & Early & 69.3 & 19.3 & 50 & 18 & 0.117 & 4.109 & 0.536 \\
\hline TR8 & Komagfjord & Norway & 1869 & Early & 70.3 & 23.4 & 10 & 16 & 0.147 & 4.641 & 0.236 \\
\hline MU1 & Rovaniemi & Finland & 1893 & Late & 66.5 & 25.7 & 80 & 20 & 0.132 & 4.531 & 0.419 \\
\hline MU69 & Muonio & Finland & 1870 & Early & 68.0 & 23.7 & 240 & 15 & 0.121 & 4.268 & 1.106 \\
\hline NM1587 & Jokkmokk & Sweden & 1867 & Early & 66.6 & 19.8 & 250 & 7 & 0.126 & 3.889 & 0.156 \\
\hline NM1597 & Kvikkjokk & Sweden & 1867 & Early & 67.0 & 17.7 & 310 & 17 & 0.046 & 2.640 & 1.141 \\
\hline NM599 & Matarengi & Sweden & 1896 & Late & 66.4 & 23.7 & 50 & 19 & 0.122 & 4.218 & 0.919 \\
\hline NM633 & Pajala & Sweden & 1896 & Late & 67.2 & 23.4 & 170 & 18 & 0.043 & 2.302 & 1.191 \\
\hline NM668 & Kurrokveik & Sweden & 1896 & Late & 66.1 & 17.9 & 420 & 18 & 0.152 & 4.754 & 0.286 \\
\hline NM669 & Vuollerim & Sweden & 1896 & Late & 66.4 & 20.6 & 110 & 20 & 0.160 & 4.922 & 0.235 \\
\hline NM727 & Sandön & Sweden & 1896 & Late & 65.5 & 22.4 & 5 & 18 & 0.135 & 4.439 & 0.362 \\
\hline NM751 & Kirtijokki & Sweden & 1896 & Late & 67.9 & 23.5 & 200 & 15 & 0.125 & 4.223 & 0.433 \\
\hline NM789 & Wouno & Sweden & 1896 & Late & 65.8 & 24.1 & 10 & 20 & 0.082 & 3.421 & 0.649 \\
\hline NM798 & Kuttainen & Sweden & 1896 & Late & 68.4 & 22.8 & 300 & 20 & 0.105 & 3.869 & 1.034 \\
\hline Total & & & & & & & & 275 & N/A & 4.364 & 0.763 \\
\hline
\end{tabular}

${ }^{a}$ Number of individuals remaining from each accession after quality control

CLUMPP merging used the Greedy Algorithm method and results were visualized with the Distruct 1.1 software (Rosenberg 2004). The optimal number of clusters was assessed using the $H^{\prime}$ statistic from CLUMPP and the $\Delta K$ value calculated as suggested by Evanno et al. (2005). In addition to analysis of the full dataset, accessions were divided into the Early and Late classes and analyzed separately in structure, to assess the geographic genetic structure within the temporal classes. DAPC was performed using the Adegenet R package (Jombart and Ahmed 2011). All principal components were used for prior group clustering and the ten most principal components were used to prevent over-fitting. The DAPC analysis was repeated 20 times and the results were merged using CLUMPP to resolve multimodality. The merged results were visualized with the Distruct 1.1 software.

\section{Analysis of covariation of genetic structure with geographic and temporal information}

To pinpoint underlying causes for the observed population clustering, as determined by structure and PCA, clustering was tested for correlation with geographic and temporal variables. Cluster membership from structure and the two most informative principal components of the PCA were tested against the latitude, longitude, altitude, country of origin and age of the accessions using a multiple linear regression. Geographic parameters (altitude, latitude and longitude) were used as numerical variables, country of origin was defined as categorical variables. The temporal variable, defined as the collection year of the accessions, was tested both as a numerical variable and as a categorial variable with the temporal classes Early or Late (Table 1). Simultaneous testing of geographic parameters and country of origin was performed using multiple linear regression models with either cluster membership from the merged structure simulations with the highest support or PC1 or PC2 score from the PCA as the regressand. Both accession-level cluster membership and individual cluster membership were used as two separate levels of testing. Accession-level data was analyzed using fixed effect models while individual level data was analyzed both with fixed effect models and mixed effect models. Since genotyping was performed on several different plates, plate identity of the samples was included as a random effect for the mixed effect models. The comparison between the two temporal classes was performed using a two-sample $t$ test, under the assumption that the data was normally distributed (confirmed through Kolmogorov-Smirnov tests). Correlations where covariations were found between explanatory variable were, additionally, analyzed using partial correlation, to compensate for the detected covariation. All statistical testing was performed using $\mathrm{R}$.

\section{Effect of sampling regime on detection of population structure}

The effect of sampling regime on detection of population structure was assessed by repeating principal component 
and structure analyses using subsets of the data, created to simulate smaller sample sizes and DNA pooling. All subsets were compared with the full dataset under the assumption that the full dataset would have a more accurate fit to the underlying genetic distribution than the subsets. Ten replicates each of single-individual and six-individual sample schemes were randomly generated from the full dataset. An artificially pooled dataset was generated using data from all individuals in each accession and used the most frequent allele for each locus in a given accession as the pooled genotype.

The $H$ ' value from the software CLUMPP after grouping the 20 replicate structure simulations for each $K$ was used to compare the robustness of the clustering and to determine whether the same number of clusters was detected for the subsets. The sum of squares of the difference in cluster assignment after CLUMPP for each subset and the full dataset for each accession was calculated and compared in R. Principal Component data were compared with Procrustes analysis using the procOPA function included in the shapes package of $\mathrm{R}$, with mirroring of axes allowed. Only the two principal components that explained the most variation were used in the analysis.

To determine whether the clustering output from the single-sample, six-sample and pooled subsets resulted in different conclusions than that from the full dataset, clustering information from structure and PCA from the subsets was subjected to the same additional analyses as the full dataset. Clustering information was tested with multiple linear regression against geographical parameters. Nonsignificant variables were excluded by order of decreasing $p$ values. A two-sample $t$-test was used for detecting codependence of clustering with temporal class.

\section{Results}

\section{Diversity within and between accessions}

Within-accession genetic diversity (Nei's $h$ ) ranged from 0.043 to 0.160 , with an average of 0.113 (Table 1 ). No significant difference was found between the withinaccession genetic diversity of the different temporal classes "Early" and "Late" (two-sample $t$-test, $M_{\text {Early }}=0.107$, $\left.\mathrm{SD}_{\text {Early }}=0.033, M_{\text {Late }}=0.118, \mathrm{SD}_{\text {Late }}=0.038, p=0.559\right)$. No significant geographic trend in within-accession diversity was observed and diversity was not correlated with either altitude, latitude, longitude or country of origin (all $p>0.05)$. Highly diverse accessions could be found both from both northern $\left(h_{\mathrm{TR} 7}=0.147\right)$ and southern parts $\left(h_{\mathrm{NM} 668}=0.152\right.$ and $\left.h_{\mathrm{NM} 669}=0.160\right)$ of the region. Large differences in within-accession genetic diversity could sometimes be seen when comparing nearby accessions. For example, the genetic diversity of NM633 $\left(h_{\mathrm{NM} 633}=0.043\right)$ differed markedly from that of its nearest neighbours NM751 $\left(h_{\mathrm{NM} 751}=0.125\right.$, distance $\left.\approx 79 \mathrm{~km}\right)$ and NM599 $\left(h_{\mathrm{NM} 599}=0.122\right.$, distance $\left.\approx 92 \mathrm{~km}\right)$, all Late accessions. On the other hand, MU69 (Early) and NM751 (Late), the accessions with the shortest geographic distance, had similar levels of genetic diversity $\left(h_{\mathrm{MU} 69}=0.121 \mathrm{vs} h_{\mathrm{NM} 751}=0.125\right.$, distance $\approx 6 \mathrm{~km}$ ).

Pairwise $F_{\mathrm{ST}}$ values between accessions across loci ranged from being slightly negative to a value of 0.362 , when comparing NM1597 with MU1 (Supplementary Table 1). Plotting $F_{\mathrm{ST}}$ values against geographic distance indicated no pattern of isolation by distance neither in the full dataset nor in the early or late groups considered separately and geographic distance and pairwise $F_{\mathrm{ST}}$ values were not significantly correlated in either dataset (all accession pairs, $c=-0.042, p=0.645$; early accession pairs, $c=0.024$, $p=0.919$; late accession pairs, $c=-0.174, p=0.310$ ). Indeed, low $F_{\mathrm{ST}}$ values were not necessarily linked to short geographic distances, in particular when comparing between temporal classes. For example, Swedish NM1587 shared most similarity with the Norwegian accession TR8 with an origin $437 \mathrm{~km}$ away but from the same age class $\left(F_{\mathrm{ST}}=0.03\right)$. NM1587 was in contrast quite different from its geographically nearest accession NM669, with an origin only $42 \mathrm{~km}$ away but belonging to a different age class $\left(F_{\mathrm{ST}}=0.15\right)$ (Table 1 , Supplementary Table 1$)$. Likewise, NM1597 was more similar to NM789, cultivated some $300 \mathrm{~km}$ away $\left(F_{\mathrm{ST}}=0.05\right)$, than the nearest accession NM668 with an origin only $100 \mathrm{~km}$ away $\left(F_{\mathrm{ST}}=0.32\right)$ (Table 1, Supplementary Table 1). $F_{\mathrm{ST}}$ comparisons between different countries of origin and different temporal classes, respectively, gave low, albeit significant, values. On a country level, $F_{\mathrm{ST}}$ indicated isolation by distance, with the largest difference between the most distantly located countries: Norway and Finland $\left(F_{\mathrm{ST}}=0.0684^{* * *}\right)$ followed by the Sweden-Norway $\left(F_{\mathrm{ST}}=0.0421 * * *\right) \quad$ and Sweden-Finland $\left(F_{\mathrm{ST}}=0.0416^{* * *}\right)$ comparisons, both with similar $F_{\mathrm{ST}}$ values. The difference between temporal classes $\quad\left(F_{\mathrm{ST}}=0.0526 * * *\right) \quad$ was lower than the Norway-Finland comparison but higher than the $F_{\mathrm{ST}}$ values of the Sweden-Norway and Sweden-Finland comparisons.

\section{Genetic structuring in northern Fennoscandian barley}

The results of the DAPC clustering were largely similar to those of the structure clustering, although with a lower proportion of admixture (Supplementary Table 2). Similarly, results from PCA and PCoA were highly correlated (accession-level PC1 vs PCo1 and PC2 vs PCo2: $c=-1$; individual level PC1 vs PCo1: $c=-0.997$; individual level PC2 vs PCo2: $c=-0.987)$. Hence, only structure and PCA 


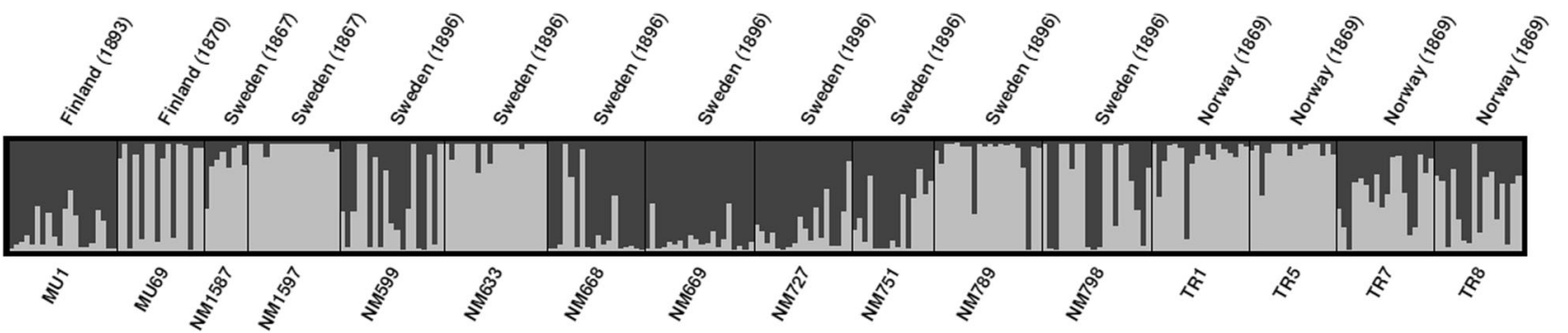

Fig. 1 Genetic structure from 20 individual structure simulations merged with the CLUMPP software for $K=2$

results are presented below. Both $H^{\prime}$ values and $\Delta \mathrm{K}$ suggested that a two-cluster model best described the distribution of the genetic diversity (Supplementary Table 3) and membership to these clusters were used downstream as the response variable in regression analysis. Five of the Early accessions (the Finnish MU69, the Swedish NM1587 and NM1597 and the Norwegian TR1 and TR5) and three of the Late accessions (the Swedish NM633, NM789 and NM798) clustered together (light grey in Figs. 1 and 2), five of the Late accessions (the Finnish MU1 and the Swedish NM668, NM669, NM727 and NM751) clustered in a second group (dark grey in Figs. 1 and 2) while the remaining accessions (NM599, TR7 and TR8) were highly admixed. Structure results from analysis of the temporal classes separately yielded similar distributions as the full dataset, without apparent geographic structure (Supplementary Tables 4 and 5).

PCA was performed both on an accession level and on an individual level. The first and second principal components explained a very high proportion of the total genetic diversity in the accession-level analysis (Fig. 3a; PC1 = $47.48 \%, \mathrm{PC} 2=14.02 \%$ ) and a smaller proportion in the individual level PCA (Fig. 3b; PC1 $=17.31 \%$, PC2 $=$ $8.90 \%)$. As expected, given the high explanatory power of PC1, the distribution of accessions along PC1 (Fig. 3a) was highly similar to the structure clustering. The individual level PCA showed a shift in the genetic composition between the Early and Late samples along both PC1 and PC2 (Fig. 3b). Despite low mean PC dispersion in the individual level PCA, NM1597 and NM633 had the highest PC-dispersion variance of the accessions studied (Table 1), indicative of within-accession substructure.

\section{Temporal class is an explanatory parameter for genetic structuring}

In the accession-level model (Table 2) no significant correlation with genetic clustering was found for either of the geographic parameters (latitude, longitude, altitude or country of origin) when the variables were tested as single regressions (all $p>0.05$ ). Population clustering was, however, significantly correlated with temporal class, both from structure clustering ( $p=0.035$ and $\left.r^{2}=0.23\right)$, PC1 $(p=$ 0.039 and $\left.r^{2}=0.12\right)$ and PC2 $\left(p=0.028\right.$ and $\left.r^{2}=0.25\right)$. The Early and Late temporal classes resulted in similarly high correlations with both cluster membership from structure (two-sample $t$-test, $p=0.0259$ ) and principal component score for PC1 (two-sample $t$-test, $p=0.029$ ). When using multiple linear regression with temporal class, latitude, longitude, altitude and country of origin as regressors the temporal link was obscured. Temporal class remained the most significant variable in the full model ( $p=0.131$ for $\mathrm{PC} 1$ and $p=0.106$ for structure clustering, Supplementary Table 6), and the effect of temporal class became significant after consecutively removing the least significant variables. Using structure clustering, temporal class became significant when longitude and latitude were excluded ( $p=0.047$ ), for PC1 when longitude was excluded $(p=0.040)$ and for PC2 when altitude, longitude and country of origin were excluded $(p=0.040)$. To assess whether this was an effect of uneven spatial sampling, correlations between harvest year (i.e., not temporal class but the actual year of harvest) and geographic origin was analyzed. Harvest year was highly correlated with both sample latitudinal origin $(r=-0.587, p=0.019)$ and longitudinal origin $(r=0.530, p=0.033)$. When using partial correlation to assess the effect of harvest year while correcting for the spurious correlation with longitude or latitude, harvest year tended to be associated with genetic clustering, although only significantly so for PC2 (structure clustering latitude $p=0.061$, longitude $p=0.098 ; \mathrm{PC} 1$ latitude $p=0.075$ longitude $p=0.098$; PC2 latitude $p=$ 0.035 , longitude $p=0.045$ ).

In the individual level model (Table 2) the effect of sample plate during genotyping, if treated as a fixed effect, was found to be non-significant $(p=0.154)$. Latitude, longitude and country of origin, but not altitude, were significantly correlated with structure clustering at the individual level if tested as single correlations (all $p<0.001$ except for altitude $p>0.05$ ), although each explained a very small portion of the variation $\left(r^{2}=0.0391,0.0470\right.$ and 0.0510 for latitude, longitude and country of origin, respectively). Similar results were found for PC1 with significant correlations but low explanatory power for 
Fig. 2 Map of spatial and temporal clustering from structure simulations for $K=2$

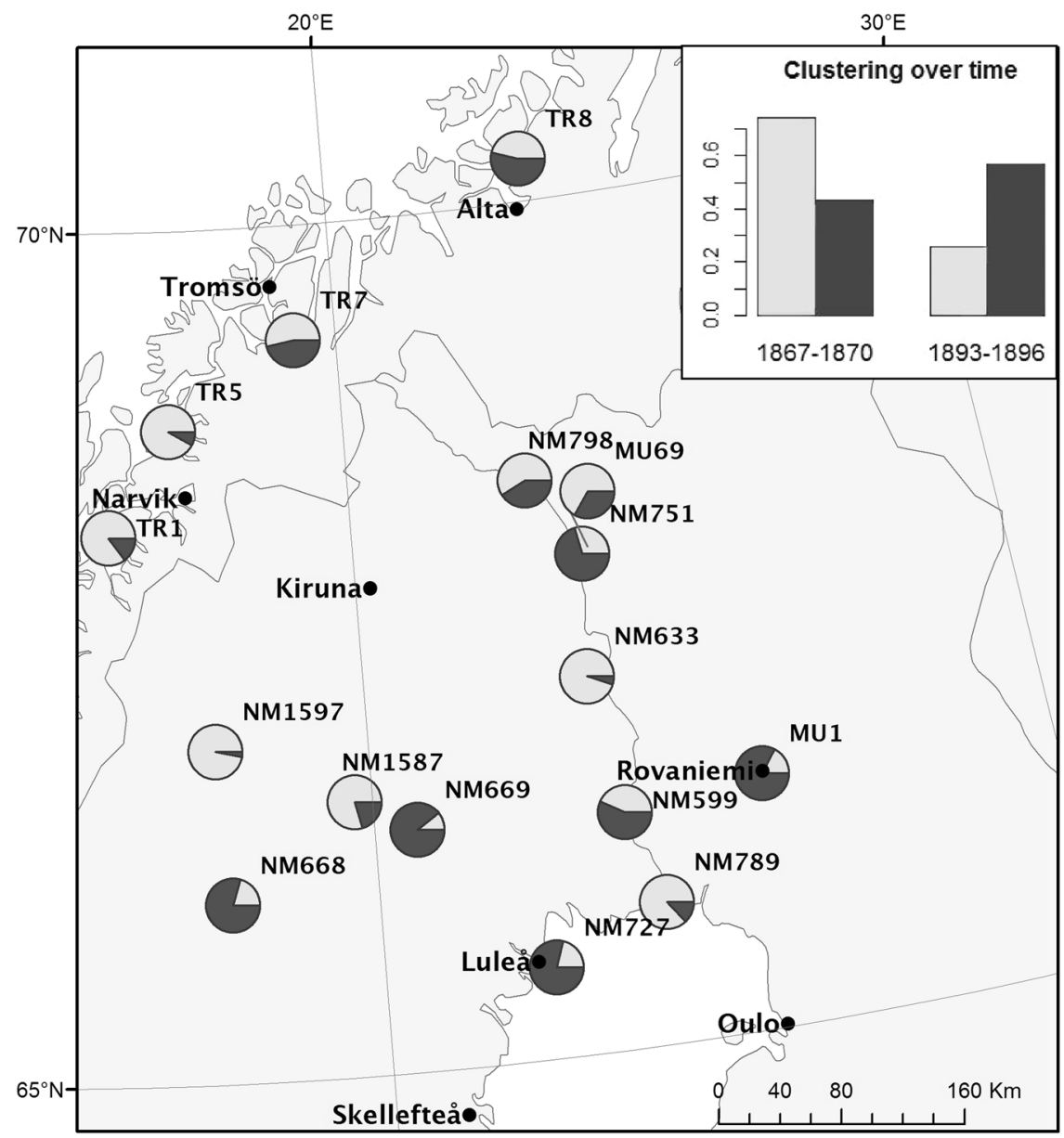

longitude, latitude and country of origin (all $p<0.001$ except latitude $p<0.01 ; r^{2}=0.0420,0.0345$ and 0.0481 for longitude, latitude and country of origin, respectively). The highest correlation and explanatory power for structure clustering and PC1 were found when testing the regression between individual cluster membership and harvest year (Table 2), which was highly significant both for structure clustering $\left(p<0.001, r^{2}=0.134\right)$ and PC1 $\left(p<0.001, r^{2}=\right.$ $0.119)$. Comparing the two temporal classes on the individual level revealed a significant difference in cluster membership from structure (two-sample $t$-test, $p<0.001$ ) and principal component score for PC1 (two-sample $t$-test, $p<0.001)$. PC2 differed slightly showing correlation with altitude $\left(p=0.029, r^{2}=0.014\right)$, country of origin $(p<$ $\left.0.001, r^{2}=0.094\right)$ and harvest age $\left(p=0.035\right.$ and $r^{2}=$ 0.013).

Using multiple linear regression with either structure clustering or $\mathrm{PC} 1$ as regressand and altitude, longitude, latitude, country of origin and temporal class as regressors, resulted in temporal class and country of origin as significant (both $p<0.001$ for both structure clustering and PC1, Supplementary Table 6). In the multiple linear regression with $\mathrm{PC} 2$, however, only country of origin was significant. Mixed effect models including sample plate as random effect yielded similar results for structure clustering and PC1 (Supplementary Table 6). Conversely, in mixed effect models for PC2 only country of origin and temporal class were significant (Supplementary Table 6).

Analyzing the genetic structure of each temporal classes separately yielded no significant geographic effects for the accession level (Supplementary Table 7). Analyzed on the individual level the longitudinal origin had the highest covariance with the genetic structure of both the Early and the Late class.

AMOVA provided additional support for the separation by age class. The bulk of the variation, some $85 \%$, was found within the accessions, with 11.13 and $12.57 \%$ of the variation present within temporal classes and countries respectively (Table 3 ). Although a minor part of the variation was found between temporal classes and among countries we note that the age class parameter explained $3.85 \%$ of the variation, whereas the country of origin parameter explained less than half the amount, $1.64 \%$, of the variation in their respective models. 
A) Population level PCA

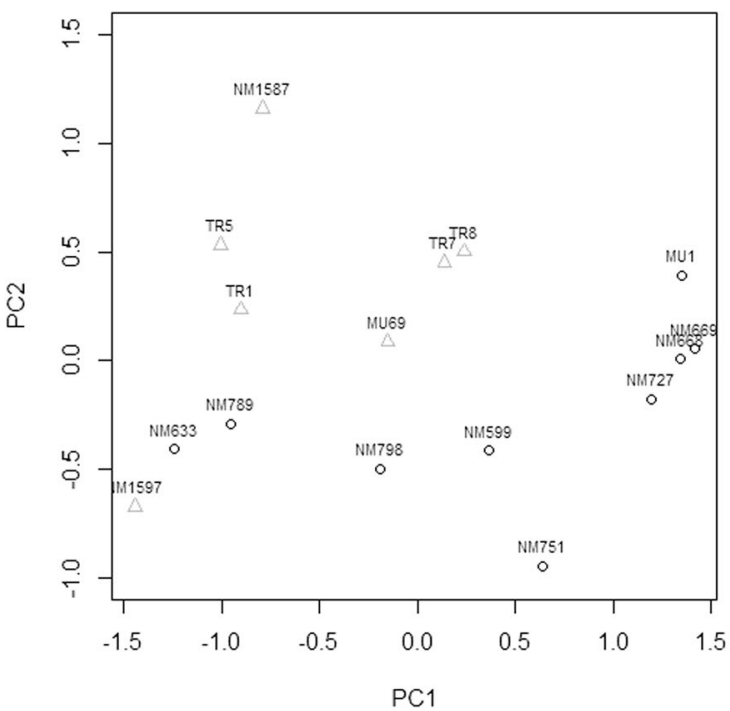

B) Individual level PCA

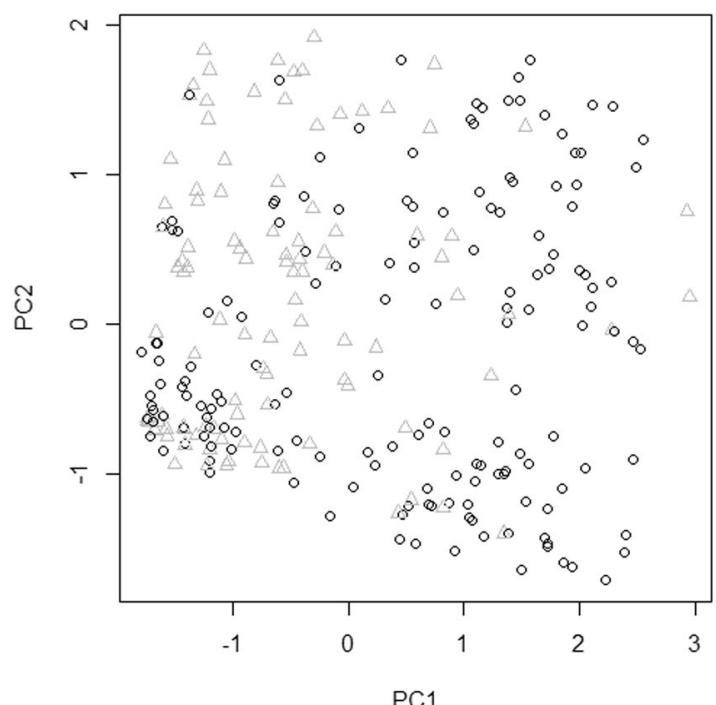

Fig. 3 PCA of SNP genotypes. Black circles signify accessions collected 1893-1896 and grey triangles signify accessions collected 1867-1870. Results from analysis at $\mathbf{a}$ accession level, and $\mathbf{b}$ individual level

Table $2 p$ and $r^{2}$ values for regression analysis of cluster membership. Negative adjusted $r^{2}$ values are given as 0 in the table

\begin{tabular}{|c|c|c|c|c|c|c|c|c|}
\hline \multirow[t]{3}{*}{ Variable } & \multicolumn{4}{|c|}{ Structure cluster membership $(K=2)$} & \multicolumn{4}{|c|}{ Principal component analysis (PC1) } \\
\hline & \multicolumn{2}{|c|}{ Accession-level } & \multicolumn{2}{|c|}{ Individual-level } & \multicolumn{2}{|c|}{ Accession-level } & \multicolumn{2}{|c|}{ Individual-level } \\
\hline & $p$ & $r^{2}$ & $p$ & $r^{2}$ & $p$ & $r^{2}$ & $p$ & $r^{2}$ \\
\hline Altitude & 0.978 & 0.000 & 0.611 & 0.000 & 0.996 & 0.000 & 0.844 & 0.000 \\
\hline Latitude & 0.366 & 0.000 & $<0.001$ & 0.039 & 0.338 & 0.000 & 0.001 & 0.035 \\
\hline Longitude & 0.208 & 0.047 & $<0.001$ & 0.048 & 0.247 & 0.030 & $<0.001$ & 0.046 \\
\hline Country & 0.589 & 0.000 & $<0.001$ & 0.051 & 0.566 & 0.000 & $<0.001$ & 0.048 \\
\hline Harvest year & 0.035 & 0.23 & $<0.001$ & 0.134 & 0.039 & 0.219 & $<0.001$ & 0.119 \\
\hline Sample plate & N/A & N/A & 0.193 & 0.005 & N/A & N/A & 0.037 & 0.017 \\
\hline
\end{tabular}

\section{Effects of sampling procedures}

Subsampling the dataset to sample sizes of one and six individuals per accession, respectively, reduced the number of informative SNPs to on average 75.6 and $97.8 \%$, respectively (Table 4). An even higher loss of information was seen in the pooled sample, where only $21.7 \%$ of the SNPs were still informative, compared with the 152 SNPs in the full dataset. Sum of Squares of difference from the structure cluster designations from the full dataset to those of the subsets showed that the six-individual sample size subsets aligned closer to the full dataset $\left(\mathrm{AvgSSQ}_{6 \text { Ind. vs Full }}=\right.$ 0.201 , sdSSQ $_{6 \text { Ind. vs Full }}=0.077$ ) than the artificially pooled subset $\left(\mathrm{SSQ}_{\text {Pool vs Full }}=0.548\right)$, and that the singleindividual subsets differed the most from the full dataset $\left(\mathrm{AvgSSQ}_{1 \text { Ind. vs Full }}=1.371, \mathrm{sdSSQ}_{1 \text { Ind. vs Full }}=0.409\right)$.
Procrustes analysis of the two major PCs revealed that all six-individual subsets but one were more similar to the PCA of the full dataset than the pooled dataset was (Table 4). The average OSS (Ordinary Procrustes Sum of Squares) for subsets was significantly smaller for the six-individual subsets compared with the pooled sample (one sample $t$-test, $p<0.001$ ), indicating that the principal components were more similar when comparing the full dataset with the six-individual subsets than with the pooled dataset. The PCA of the subsets using single individuals differed by far the most from the PCA of the full dataset (one sample $t$-test, $p<0.001)$.

The correlations between population structure and temporal and geographic parameters were also analyzed for the subsets and compared with those of the full dataset (Supplementary Table 8). Co-dependence with temporal class 
Table 3 AMOVA of the genotypes of the studied accessions

\begin{tabular}{llllll}
\hline Group & Source of variation & d.f. & Sum of Squares & Variance components & $\%$ of variation \\
\hline Temporal classes & Among temporal classes & 1 & 73.914 & 0.3632 & 3.85 \\
& Among accessions within temporal classes & 14 & 370.03 & 1.07453 & 11.38 \\
& Within populations & 259 & 2072.663 & 8.00256 & 84.77 \\
& Total & 274 & 2516.607 & 9.44028 & 0.15261 \\
Countries & Among countries & 2 & 79.539 & 1.1724 & 1.64 \\
& Among accessions within countries & 13 & 364.405 & 8.00256 & 12.57 \\
& Within populations & 259 & 2072.663 & 9.32757 & 85.79 \\
\hline
\end{tabular}

Table 4 Number of informative SNPs and ordinary Procrustes sum of squares (OSS) in the subsets

\begin{tabular}{|c|c|c|c|}
\hline \multirow[b]{2}{*}{ Set } & \multicolumn{2}{|c|}{ Informative SNPs } & \multirow{2}{*}{$\begin{array}{l}\text { Procrustes analysis } \\
\text { Average OSS (s.d.) }\end{array}$} \\
\hline & Average (s.d.) & Proportion & \\
\hline Full & 152 (NA) & 1 & NA (NA) \\
\hline 1 individual/population & $114.9(8.279)$ & 0.756 & $13.640(2.370)$ \\
\hline 6 individuals/population & $148.6(1.174)$ & 0.978 & $2.723(0.872)$ \\
\hline Artificial pooling & 33 (NA) & 0.217 & 4.141 (NA) \\
\hline
\end{tabular}

could only be detected in one out of the ten single-sample subsets. Significant correlations with altitude $(p<0.05)$ were detected in two single-sample subsets. In the sixsample subsets significant correlations with age class was detected in four out of ten subsets for PC1 and structure clustering and five of ten subsets for PC2. The artificially pooled dataset found the same co-dependence with temporal class as the full dataset and an additional correlation between latitudinal origin of the accessions and structure clustering.

\section{Genotype sharing suggest long distance seed exchange}

Individuals sharing the same total genotypes, where every scored SNP was identical, were found both within and among accessions. Six groups of shared total genotypes that included individuals from multiple accessions, an indication of seed exchange, were found. Three of these included more than three individuals (Supplementary Table 9). The majority of the three most common shared total genotypes (genotype 1-3 in Supplementary Table 9) were found in accessions from the Torne Valley (MU69, NM599, NM633, NM798 and NM789) along the Swedish-Finnish border (Fig. 4). The most common shared total genotype (genotype 1 in Supplementary Table 9), which occurred in 16 copies, was primarily shared between the least diverse accessions, with six copies occurring in NM1597 and four copies in
NM633. In contrast with the Torne Valley accessions, these two accessions were from geographically distant localities.

\section{Discussion}

Using a large number of individuals from each studied accession increased our power to detect fine-scale genetic structure in a geographic region that had previously seemed genetically relatively homogeneous (Forsberg et al. 2015). Although geographic origin was associated with genetic structuring parameters, sampling time point better explained the genetic distribution of the data. The 30-year span separating the Early and Late accessions is infamous for the repeated crop failures occurring in the region.

Disastrous events have throughout history led to failure of food production and subsequent risk of starvation. In many cases relief efforts, either in the shape of food, or through supplies aiming to restore agricultural production, have alleviated the consequences. Modern examples are the restoration of agriculture after the hurricane Mitch disaster in Honduras in 1998 and the civil war in Rwanda 1994-1996. In both cases replacement seed from the CGIAR institutes played an important role (Varma and Winslow 2004). However, seed relief risks narrowing the local crop gene pool and introduce less adapted genotypes (Ferguson et al. 2012). Seed relief may thus affect the longterm efficiency of local agriculture. 
Fig. 4 Geographic distribution of three most common shared genotypes shown as bar plots at the geographic location of origin. The height of the bars shows prevalence of the different shared genotypes

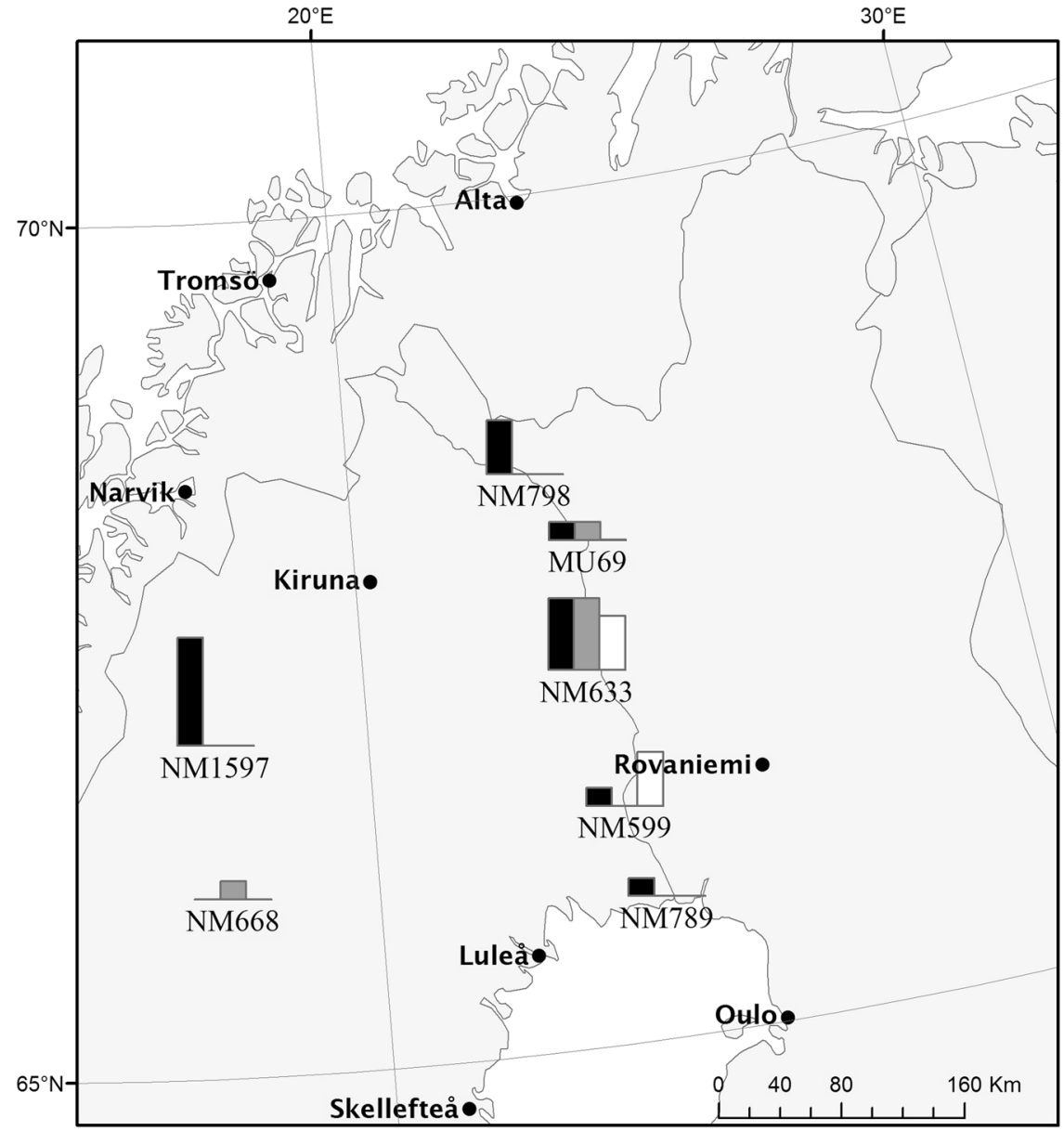

During the worst years of crop failure in northern Sweden in the 1860s, many farmers had no seed for the spring sowing. After the most devastating year, 1867, seed shortage was described as a general and severe problem in the yearly agricultural reports collected by the regional Rural Economy and Agricultural Society (Rydstedt et al. 1868). The following year, the same source reports that many farmers had planted seed imported from more southerly locations (Finell et al. 1869). Our findings of temporal genetic structure during this time period corroborate these reports and suggest that the composition of plant material changed as a result of seed aid and import and that replacement seed was not only acquired locally. Although both major clusters detected here were present in both temporal classes, there was a considerable shift in the distribution of cluster membership (Fig. 2) when comparing accessions collected during the early famine years, 1867-1870 (Early accessions), to accessions collected 1893-1896, after the famine (Late accessions).

Population crashes are expected to lead to a reduction in the genetic diversity through increased genetic drift during the population bottleneck (Nei et al. 1975). We were, however, unable to detect any general reduction in within- accession genetic diversity among the late accessions. Ferguson et al. (2012) showed that the genetic composition of cowpea changed significantly after a severe flood in Mozambique in 2000, while maintaining a similar level of diversity. Similarly, the varietal composition, but not overall diversity, of beans in Rwanda was affected by the civil war in 1994-1996 (Sperling 2001). The same pattern seems to have followed the 19th century crop failure in Northern Fennoscandia. The dependency of agrarian societies on crop plants for their sustenance means that crop failure calls for supplementary seed to be brought in from other regions. An input of new genetic diversity is thus expected to follow the reduction in population size, which could manifest itself in a shift in the structuring of the genetic diversity such as the one detected here. An input of new seed would also counteract the loss of genetic variation following a population crash and could explain why not such loss was detected here.

Although the study area is vast and covers several different bio-climatic zones (Karlsen et al. 2006) previous studies have shown no significant geographic structure in barley within Northern Fennoscandia (Leino and Hagenblad 2010; Forsberg et al. 2015). Genetic structuring is 
associated with some of the geographic parameters investigated in this study. However, the associations are weaker than the temporal associations and may be an effect of uneven sampling with regards to sample age. Hellström (1917) describes barley from northern Sweden as being phenotypically relatively variable but suggests that differences were primarily evident in comparisons between landraces from different altitudes rather than latitudes or different municipalities. In this study we did not detect any relationship between altitude and genetic clustering. Unfortunately, contemporary metrological data are not detailed enough to allow for further genetic-climatic correlations and use of modern-day climatic data is problematic, as climate has changed quite dramatically in this region during the past 150 years. Bio-climatic zones and important agricultural parameters such as length of growth season do, however, depend primarily on latitude and altitude in this area (Karlsen et al. 2006), parameters with only minor correlation, and lesser than that of sample age, with genetic structuring among the samples studied here.

While the use of historical seed allows us to study past temporal and geographic distribution of genetic diversity, access to samples limits the quality of sampling. It was not possible to obtain a geographically even distribution of Early and Late accessions from the area studied. For example, all the Norwegian accessions are Early accessions while the majority of the Swedish accessions are Late. It is therefore possible that the detected difference between Early and Late accessions also has a geographical component that cannot be discerned from the available historical material. Lacking any possibility of improving the sampling, we tentatively note that in the two cases with Early and Late accessions from the same area (the Early MU69 vs the Late NM751 and the Early NM1587 vs the Late NM669) we do see a larger than average shift in the genetic clustering ( $\Delta$ Clustering ${ }_{\mathrm{MU} 69-\mathrm{NM} 751}=0.47$ and $\Delta$ Clustering $_{\mathrm{NM} 1587-\mathrm{NM} 699}=0.69, \Delta$ Clustering $_{\text {Early-Late }}=0.31$ ).

The detection of temporal genetic structure was made possible by the large number of individuals analyzed from each accession. Neither the single-individual nor the sixindividual subset samples were able to reliably detect the temporal shift in genetic structuring identified in the full dataset. The sampling of within-accession diversity has been shown to aid in the correct identification of genetic structure (Fogelqvist et al. 2010; Hagenblad et al. 2017) and our results corroborate these findings. In this study we find that the artificial pooling scheme, despite vastly reducing the number of informative SNPs, found the same significant correlations with age class as the full dataset, but performed worse than the six-individual sampling in terms of detecting the same genetic structure in structure and PC analyses. Pooling a large number of individual DNA extracts may be as useful as studying a small number of seeds on an individual basis, and is preferable to sampling single individuals in cases where the cost of genotyping is a limiting factor. It should, however, be noted that the required number of individuals per accession also depends on the diversity among accessions and the research questions being asked. In this study we found a pronounced need for a large sample size for assessing genetic structure since the genetic change over time was relatively small. In studies were the genetic variation between accessions is small relative to the genetic variation within accessions we advise the use of several tens of individuals per accession.

Individuals sharing a total genotype were detected among the accessions along the long-established trade route of the Torne valley (Groth 1984), and the total genotype sharing, and in several cases low $F_{\mathrm{ST}}$ values between Torne Valley accessions, is likely the result of seed exchange in this area. This is an example of local networks of seed exchange in areas with common infrastructure and agricultural conditions. Such systems are regularly formed in agrarian societies depending on landrace cultivation (Thomas et al. 2011) and recent day examples show the particular importance of such systems after disastrous events (Sperling 2001). Seed trade was, however, probably not ubiquitous in the area. The low genetic diversity of NM1597 (Kvikkjokk) and high $F_{\mathrm{ST}}$ values between NM1597 and the neighbouring NM1587, NM668 and NM669 instead suggests isolated farming in Kvikkjokk, tentatively also with bottleneck effects from the agriculturally very demanding conditions described in the area by contemporary sources (Laestadius 1824).

The high degree of total genotype sharing between NM1597 from Kvikkjokk and several accessions in the Torne valley, almost $300 \mathrm{~km}$ apart, is puzzling, but has a possible historical explanation. The seeds from Kvikkjokk (NM1597), characterized by a high presence of Genotype 1 (six out of 17 genotyped individuals), were donated by Johan Laestadius, vicar of Kvikkjokk 1860-1870. Johan's uncle Lars-Levi Laestadius provides a historical link between most sites with Genotype 1. L.L. Laestadius was an early 19th century vicar and botanist from Kvikkjokk with a considerable interest in agronomy. In 1826 L.L. Laestadius took up a position as vicar in Karesuando and in 1849 in Pajala. These two localities are the origins of the two accessions NM798 and NM633, respectively, which contain the largest proportion of Genotype 1 outside of NM1597. Whether the botanist and vicar or his family, upon moving, brought seeds with them and thereby influenced the genetic composition of barley in the Torne region, can probably never be established beyond speculation. Nevertheless, the possible effect of influential individuals on the distribution of genetic diversity of cultivated crops cannot be disregarded and remains a tantalizing thought. 


\section{Conclusions}

By genetic analysis of a large number of samples per accession we have shown how the genetic composition of landrace barley in northern Fennoscandia changed during the latter part of the 19th century. This change occurred during a period characterized by repeated crop failures in the area, and the need for replacement seed after severe crop failure is most likely the cause of the observed genetic change. This adds to the results of studies of more recent crop failures suggesting that genetic composition, but not genetic diversity, is primarily affected by severe crop failure.

\section{Data availability}

Genotype data available from the Dryad Digital Repository: https://doi.org/10.5061/dryad.qv9s4mw9b.

Acknowledgements This work was funded by the Norwegian institute of Science and Technology (NTNU), the Helge Ax:son Johnsons Foundation, the Hem i Sverige-fonden Foundation, the CF Lundström Foundation and the Swedish Research Council for Environment, Agricultural Sciences and Spatial Planning (FORMAS) grant number 2018-02845. Plant material was kindly provided from Mustiala Agricultural College with the help of Annika Michelson and Hannu Ahokas and from Tromsø University Museum with the help of Torbjørn Alm.

\section{Compliance with ethical standards}

Conflict of interest The authors declare that they have no conflict of interest.

Publisher's note Springer Nature remains neutral with regard to jurisdictional claims in published maps and institutional affiliations.

\section{References}

Abdel-Ghani AH, Parzies HK, Omary A, Geiger HH (2004) Estimating the outcrossing rate of barley landraces and wild barley populations collected from ecologically different regions of Jordan. Theor Appl Genet 109:588-595

Bergman I, Hörnberg G (2015) Early cereal cultivation at Sámi settlements: challenging the Hunter-Herder paradigm? Arct Anthropol 52:57-66

Bjørnstad A, Abay F (2010) Multivariate patterns of diversity in Ethiopian barley. Crop Sci 50:1579-1586

Demissie A, Bjørnstad Å (1997) Geographical, altitude and agroecological differentiation of isozyme and hordein genotypes of landrace barleys from Ethiopia: implications to germplasm conservation. Genet Res Crop Evol 44:43-55. https://doi.org/10. 1023/A:1008686009866

Dribe M, Olsson M, Svensson P (2015) Famines in the Nordic countries, AD 536-1875. No. 138. Lund University, Department of Economic History

Evanno G, Regnaut S, Goudet J (2005) Detecting the number of clusters of individuals using the software STRUCTURE: a simulation study. Mol Ecol 14:2611-2620
Excoffier L, Lischer HEL (2010) Arlequin suite ver 3.5: a new series of programs to perform population genetics analyses under Linux and Windows. Mol Ecol Resour 10:564-567

Excoffier L, Smouse PE, Quattro JM (1992) Analysis of molecular variance inferred from metric distances among DNA haplotypes: application to human mitochondrial DNA restriction data. Genetics 131:479-491

Falush D, Stephens M, Pritchard JK (2007) Inference of population structure using multilocus genotype data: dominant markers and null alleles. Mol Ecol Notes 7:574-578

Ferguson ME, Jones RB, Bramel PJ, Domínguez C, Torre do Vale C, Han J (2012) Post-flooding disaster crop diversity recovery: a case study of Cowpea in Mozambique. Disasters 36:83-100

Finell JM, Burman GD, Rehausen W, von, Fogelmarck SU, Sjöstedt U, Hummel D, et al. (1869) Hushållsgillenas årsberättelser Norrbottens läns hushållningssällskaps handlingar. Norrbottens läns hushållningssällskap, Luleå, p. 43-66

Fogelqvist J, Nittyvuopio A, Ågren J, Savolainen O (2010) Cryptic population genetic structure: the number of inferred clusters depends on sample size. Mol Ecol Resour 10:314-323

Forsberg N, Russell J, Macaulay M, Leino M, Hagenblad J (2015) Farmers without borders-genetic structuring in century old barley (Hordeum vulgare). Heredity 114:195-206

Fuentes F, Bazile D, Bhargava A, Martínez E (2012) Implications of farmers' seed exchanges for on-farm conservation of quinoa, as revealed by its genetic diversity in Chile. J Agric Biol Sci 150:702-716

Grotenfelt G (1896) Landtbruket i Finland: en öfversikt. Hagelstam, Helsingfors

Groth Ö (1984) Norrbotten 1. In Norrbottens historia. Skrivarförlaget/ Norrbottens bildningsförbund, Luleå

Grym E (1959) Från Tornedalen till Nordnorge. Luleå Bokförlag, Luleå

Hagenblad J, Morales J, Leino MW, Rodríguez-Rodríguez AC (2017) Farmer fidelity in the Canary Islands revealed by ancient DNA from prehistoric seeds. J Archaeol Sci 78:78-87

Hellström P (1917) Norrlands jordbruk. Almqvist \& Wiksell, Uppsala

Häger O, Torell C, Villius H (1978) Ett satans år: Norrland 1867. Sveriges radio, Stockholm

Jakobsson M, Rosenberg NA (2007) CLUMPP: a cluster matching and permutation program for dealing with label switching and multimodality in analysis of population structure. Bioinformatics 23:1801-1806

Jantunen J, Ruosteenoja K (2000) Weather conditions in northern Europe in the exceptionally cold spring season of the famine year 1867. Geophysica 36:69-84

Jombart T, Devillard S, Balloux F (2010) Discriminant analysis of principal components: a new method for the analysis of genetically structured populations. BMC Genet 11:1-15

Jombart T, Ahmed I (2011) adegenet 1.3-1: new tools for the analysis of genome-wide SNP data. Bioinformatics 27:3070-3071

Jones RB, Bramel P, Longley C, Remington T (2002) The need to look beyond the production and provision of relief seed: Experiences from Southern Sudan. Disasters 26:302-315

Jones H, Civan P, Cockram J, Leigh FJ, Smith LMJ, Jones MK, et al. (2011) Evolutionary history of barley cultivation in Europe revealed by genetic analysis of extant landraces. BMC Evol Biol 11.1:320

Josefsson T, Hörnberg G, Liedgren L, Bergman I (2017) Cereal cultivation from the Iron Age to historical times: evidence from inland and coastal settlements in northernmost Fennoscandia. Veg Hist Archaeobot 26:259-276

Karlsen SR, Elvebakk A, Høgda KA, Johansen B (2006) Satellitebased mapping of the growing season and bioclimatic zones in Fennoscandia. Glob Ecol Biogeogr 15:416-430 
Laestadius LL (1824). Om möjligheten och fördelen af allmänna uppodlingar i Lappmarken. Zacharias Haeggström, Stockhholm

Leino MW (2010) Frösamlingar på museum. Nordisk Museol 1:96-108

Leino MW, Hagenblad J (2010) Nineteenth century seeds reveal the population genetics of landrace barley (Hordeum vulgare). Mol Biol Evol 27:964-973

Leino MW, Hagenblad J, Edqvist J, Strese EMK (2009) DNA preservation and utility of a historic seed collection. Seed Sci Res 19:125-135

Lempiäinen-Avci M, Lundström M, Huttunen S, Leino MW, Hagenblad J (2018) Archaeological and historical materials as a means to explore Finnish crop history. Environ Archaeol 1-16. https:// doi.org/10.1080/14614103.2018.1482598

Londo JP, Chiang Y-C, Hung K-H, Chiang T-Y, Schaal BA (2006) Phylogeography of Asian wild rice, Oryza rufipogon, reveals multiple independent domestications of cultivated rice, Oryza sativa. Proc Natl Acad Sci USA 103:9578-9583

Moragues M, Comadran J, Waugh R, Milne I, Flavell AJ, Russell JR (2010) Effects of ascertainment bias and marker number on estimations of barley diversity from high-throughput SNP genotype data. Theor Appl Genet 120:1525-1534

Nei M (1973) Analysis of gene diversity in subdivided populations. Proc Natl Acad Sci USA 70:3321-3323

Nei M, Maruyama T, Chakraborty R (1975) The bottleneck effect and genetic variability in populations. Evolution 29:1-10

Nelson MC (1988) Bitter Bread: the Famine in Norrbotten 1867-1868, $\mathrm{PhD}$ thesis Uppsala University

Nordborg M, Hu TT, Ishino Y, Jhaveri J, Toomajian C, Zheng H, et al. (2005) The pattern of polymorphism in Arabidopsis thaliana. PLoS Biol 3:e196

Oliveira HR, Campana M, Jones H, Hunt H, Leigh F, Lister DL, et al. (2012) Tetraploid wheat landraces in the Mediterranean basin: taxonomy, evolution and genetic diversity. PLoS ONE 7:e37063

Olsen KM, Schaal BA (1999) Evidence on the origin of cassava: phylogeography of Manihot esculenta. Proc Natl Acad Sci USA 96:5586-5591

Osvald H (1959). Åkerns nyttoväxter. Sv. litteratur, Stockholm

Papa R, Attene G, Barcaccia G, Ohgata A, Konishi T (1998) Genetic diversity in landrace populations of Hordeum vulgare L. from
Sardinia, Italy, as revealed by RAPDs, isozymes and morphophenological traits. Plant Breed 117:523-530

Pitkänen K (1992) The patterns of mortality during the Great Finnish Famine in the 1860s. Acta Demographica 1992:81-102

Popescu AA, Huber KT, Paradis E (2012) ape 3.0: new tools for distance based phylogenetics and evolutionary analysis in $\mathrm{R}$. Bioinformatics 28:1536-1537

Pritchard JK, Stephens M, Donnelly P (2000) Inference of population structure using multilocus genotype data. Genetics 155:945-959

Rosenberg NA (2004) DISTRUCT: a program for the graphical display of population structure. Mol Ecol Notes 4:137-138

Rydstedt G, Burman GD, Jacobsson JD, Schönfelt RF, Rehausen W von, Berghmark D, et al. (1868) Hushållsgillenas årsberättelser. Norrbottens läns hushållningssällskaps handlingar. Norrbottens läns hushållningssällskap, Luleå, p. 46-75

Statistiska centralbyrån Landshövdingeämbetet i Norrbottens län (1856-1905) Femårsberättelser Norrbottens län, 1856-1905. In: Bidrag till Sveriges officiella statistik. H Kungl Maj:ts befallningshafvandes femårsberättelser. Statistiska centralbyrån Landshövdingeämbetet i Norrbottens län, Stockholm

Sperling L (2001) The effect of the civil war on Rwandas bean seed systems and unusual bean diversity. Biodivers Conserv 10:989-1010

Thomas M, Dawson JC, Goldringer I, Bonneuil C (2011) Seed exchanges, a key to analyze crop diversity dynamics in farmer-led on-farm conservation. Genet Res Crop Evol 58:321-338

Tilastokeskus (1875) Finlands Officiella Statistik II: Öfversigt af Finlands ekonomiska tillstånd åren 1866-1870. Statistikcentralen, Helsinki

Yelome IO, Audenaert K, Landschoot S, Dansi A, Vanhove W, Silue D, et al. (2018) Analysis of population structure and genetic diversity reveals gene flow and geographic patterns in cultivated rice ( $O$. sativa and $O$. glaberrima) in West Africa. Euphytica 214:215

Varma S, Winslow M (2004) Healing wounds: how the international centers of the CGIAR help rebuild agriculture in countries affected by conflicts and natural disasters. Consultative Group on International Agricultural Research (CGIAR), Washington, DC.

Weir BS, Cockerham CC (1984) Estimating F-statistics for the analysis of population structure. Evolution 38:1358-1370 